\title{
Water/Oil Pickering Emulsion Stabilized by Magnesium Oxide Particles: A Potential System with Two Active Substances (Paracetamol and Griseofulvin)
}

\author{
Papa Mady Sy1*, Alphonse Rodrigue Djiboune1, Louis Augustin Diaga Diouf1, \\ Mamadou Soumboundou', Boucar Ndong', Augustin Ndiaye1, Sidy M. Dieng', Ousseynou Diop², \\ El Hadji A. L. Bathily², Gora Mbaye1* ${ }^{*}$ Mack Faye1, Mamadou Mbodj², Mounibé Diarra1* \\ ${ }^{1}$ Laboratory of Physics and Pharmaceutical Biophysics, Faculty of Medicine, Pharmacy and Odontology, UCAD, Dakar, Senegal \\ ${ }^{2}$ Laboratory of Medical Biophysics and Nuclear Medicine, Faculty of Medicine, Pharmacy and Odontology, UCAD, Dakar, Senegal \\ Email: *madyspa@gmail.com, *mbaygo@yahoo.fr, *mounbeni@yahoo.fr
}

How to cite this paper: Sy, P.M., Djiboune, A.R., Diouf, L.A.D., Soumboundou, M., Ndong, B., Ndiaye, A., Dieng, S.M., Diop, O., Bathily, E.H.A.L., Mbaye, G., Faye, M., Mbodj, M. and Diarra, M. (2018) Water/Oil Pickering Emulsion Stabilized by Magnesium Oxide Particles: A Potential System with Two Active Substances (Paracetamol and Griseofulvin). Open Journal of Biophysics, 8, 68-84.

https://doi.org/10.4236/ojbiphy.2018.82006

Received: March 30, 2018

Accepted: April 24, 2018

Published: April 27, 2018

Copyright $\odot 2018$ by authors and Scientific Research Publishing Inc. This work is licensed under the Creative Commons Attribution International License (CC BY 4.0).

http://creativecommons.org/licenses/by/4.0/

(c) (i) Open Access

\begin{abstract}
Pickering emulsions are systems without surfactants, stabilized by solid particles. These emulsions are experiencing a renewed interest, on the one hand, because it is preferable to limit the use of synthetic surfactants for toxicological and environmental reasons and, on the other hand, the need to make new formulations in order to control the drug release patterns by encapsulation or controlled release. Thus, we were interested in the formulation and evaluation of W/O Pickering emulsions stabilized by particles of magnesium oxide with paracetamol in the internal phase and griseofulvin in the external phase. The Bancroft rule served as a model for the formulation. The emulsification was carried out by progressively adding an aqueous phase dispersed in an oil-dispersing phase using a turbo rotor stator mixer. The stability of these emulsions was studied using several parameters (droplet size, $\mathrm{pH}$, viscosity, conductivity ...) and the qualitative and quantitative analysis of the active ingredients by UV-visible spectrophotometry. The results obtained showed that the dye test and the conductivity measurement confirmed the W/O nature of these emulsions. Some parameters such as droplet size, $\mathrm{pH}$ and viscosity were strongly influenced by the amounts of magnesium oxide particles and the two active ingredients used. The qualitative and quantitative analysis of the active ingredients confirmed the presence of griseofulvin in the oil phase and paracetamol in the aqueous phase. Thus, we have succeeded in developing a stable W/O Pickering emulsion with magnesium oxide particles. In addition, we were able to incorporate paracetamol into the dispersed phase and griseofulvin into the
\end{abstract}


dispersing phase of the emulsion.

\section{Keywords}

Emulsion, Pickering-Mgo-Griseofulvin-Paracetamol

\section{Introduction}

Pickering emulsions are dispersions of two immiscible liquids stabilized by solid particles. They are generally composed of three components: aqueous phase, oil phase and stabilizing solid particles. The stabilizing effect of emulsions by solid particles has been known for about a century. These emulsions are called "Pickering Emulsions" named after one of the earliest researchers who described this type of stabilization. It has established that particles can act as surfactants and stabilize oil-in-water emulsions. However, the first description of this phenomenon is due to Ramsden; his work was cited by Pickering [1] [2]. Currently, there is renewed interest in Pickering emulsions. Their "surfactant-free" character makes them attractive for different applications where surfactants often show adverse effects (irritation, haemolytic behaviour, environmental problems ...) [3]. In addition, one of the main advantages of Pickering emulsions is that they are more stable than other types of emulsions. The adsorption of solid particles at the oil-water interface is strong and irreversible. This leads to the formation of a dense film thus creating a barrier around the droplets giving them a high resistance to coalescence. The particle adsorption or desorption energy $\left[\Delta \mathrm{E}=\gamma_{\mathrm{HE}}\right.$ $\left.\pi \mathrm{r}^{2}(1 \pm \cos \theta)^{2}\right]$ is mainly related to their ability to be partially wetted by the two phases of the emulsion [4] [5] [6]. This wetting of the particles is characterized by an angle of contact between the aqueous phase, the oil phase and the solid particles, measured on the side of the aqueous phase. Thus, the particles having a contact angle of less than $90^{\circ}$ are usually called hydrophilic and preferably stabilize the $\mathrm{O} / \mathrm{W}$ type emulsions whereas those whose contact angle is less than $90^{\circ}$ are called hydrophobic and are used to stabilize W/O type emulsions [7]. Pickering emulsions also offer the possibility of being stabilized by varieties of particles such as metal oxides and hydroxides, silica, clays, laponite, etc. [7] [8] [9] [10]. The Magnesium Oxide used in this study can be used in several fields. In food, it is used as a food additive. It can also be used as an antacid in heartburn [11].

In this study, we are interested in the formulation and evaluation of a Pickering emulsion stabilized by particles of Magnesium Oxide. From this first formulation, we chose the most stable emulsions in order to incorporate paracetamol into the internal aqueous phase. Finally, in the stable emulsion containing paracetamol in its internal phase, we incorporated griseofulvin in the external oily phase. Some parameters such as droplet size, viscosity, $\mathrm{pH}$, extraction and dosage of the active ingredients have been widely studied and discussed in this work. 


\section{Materials and Methods}

\subsection{Materials}

The oily phase used throughout the study is a mixture of extra virgin olive oil Hojiblanca ${ }^{\circledR}$ from the market mainly composed of mono-unsaturated, polyunsaturated fatty acid and saturated fatty acid and petroleum jelly. The particles used for stabilization are Magnesium Oxide $(\mathrm{MgO})$ Normapur ${ }^{\circledR}$ batch number 71329 from RHONE-POULENC laboratories. The aqueous phase used is distilled water. The active ingredients used are paracetamol batch number RI0081 and griseofulvin batch number 48044 was supplied by the pharmaceutical industry WINTHROP PHARMA SENEGAL (SANOFI AVENTIS Group).

Various other chemicals were used during the different stages of this study: Sudan III, ethanol (SCHARLAU ET0005). All the chemicals were analytical grade and used as received.

\subsection{Methods}

\subsubsection{Formulation of Pickering Emulsions}

During the formulation, the direction of the emulsion formed is one of the most important properties and characteristics. The Bancroft rule, which states that the type of emulsion depends on the medium in which the particles are introduced initially, served as a model for the preparation of the formulations.

\section{1) Preparation of the dispersing Oil Phase:}

In the petroleum jelly, the magnesium oxide is progressively added by triturating until homogenization takes place. To this mixture was added olive oil containing griseofulvin and then subjected to agitation for 3 minutes at $1680 \mathrm{rpm}$.

\section{2) Preparation of the dispersed aqueous phase:}

The amount of paracetamol to be incorporated in distilled water is dissolved. The mixture is homogenized with a magnetic stirrer at $1000 \mathrm{rpm}$ for one minute.

\section{3) Emulsification:}

In the suspension previously prepared, the aqueous phase is gradually added followed by the fragmentation of the drops of water with the aid of the mixer. Subsequently, the final mixture is homogenized vigorously for one minute at $1680 \mathrm{rpm}$. The total time of preparation of the emulsion is five minutes. The preparation of all the emulsions of this work was carried out under the same operating conditions (stirring speed, stirring time, type of stirrer, temperature). Thus, three series of emulsions were prepared: An W/O emulsion without active ingredient, a W/O emulsion containing paracetamol in the internal phase and an $\mathrm{W} / \mathrm{O}$ emulsion containing paracetamol in the internal aqueous phase and griseofulvin in the outer oily phase.

Thus, we prepared the Pickering emulsions in the following proportions (Table 1).

\subsubsection{Characterization of Emulsions}

\section{1) Bottle test:}

The emulsions are left to rest in the absence of light and an ambient temperature 
Table 1. Proportions of formulations.

\begin{tabular}{ccccccccccccc}
\hline Tubes & T1 & T2 & T3 & T4 & T5 & T6 & T'1 & T’2 & T'3 & T'4 & T'5 & T'6 \\
\hline Oil (g) & 27.3 & 27.3 & 27.3 & 27.3 & 27.3 & 27.3 & 27.3 & 27.3 & 27.3 & 27.3 & 27.3 & 27.3 \\
Water (g) & 30 & 30 & 30 & 30 & 30 & 30 & 30 & 30 & 30 & 30 & 30 & 30 \\
MgO (g) & 4 & 4 & 4 & 4 & 4 & 4 & 6 & 6 & 6 & 6 & 6 & 6 \\
Vaseline (g) & 30 & 30 & 30 & 30 & 30 & 30 & 30 & 30 & 30 & 30 & 30 & 30 \\
Paracetamol (mg) & 0 & 250 & 0 & 125 & 250 & 500 & 0 & 250 & 0 & 125 & 250 & 500 \\
Griseofulvin (mg) & 0 & 0 & 50 & 25 & 50 & 75 & 0 & 0 & 50 & 25 & 50 & 75 \\
\hline
\end{tabular}

in $50 \mathrm{ml}$ conical bottle tests. This visual inspection makes it possible to demonstrate certain phenomena of instability such as sedimentation, flocculation and coalescence.

\section{2) Direction of the emulsions:}

It is carried out by a measurement of the electrical resistance of the external phase of the emulsion. The measuring cell is introduced into a $50 \mathrm{ml}$ conical bottle test containing the emulsion. Be sure to place the electrode at the emulsified phase for the sediment tubes.

We also used the dye test. It is based on the determination of the solubility of the Sudan III in the emulsion obtained. Place two milliliters of the emulsion to be tested in a watchglass. Add few grams of Sudan III and mix. After assembly between blade and slide, observation will be done under optical microscope Axio Zeiss imager A1 coupled to a computer containing the Axio Vision software rel. Version 4.5 (Zeiss optical microscope).

\section{3) Droplet size measurements:}

The technique used is based on the estimation of the mean number diameter of the droplets by individual counting. The light chamber microscope BBT KRAUSS was used for measurements.

\section{4) $\mathrm{pH}$ of the emulsions:}

As for the conductivity, care must be taken to introduce the electrode up to the emulsified phase level for the sediment tubes. The reading time is set to three minutes after insertion of the electrode.

\section{5) Viscosity of the emulsions:}

The viscosity measurements were carried out using a BROOKFIELD viscometer pro VII. The principle of measuring the viscosity retained by Brookfield relies on the application of a force of movement to a product by rotating at a fixed speed a mobile of fixed size. The resistance of the product to the rotational movement of the mobile is recorded by means of an internal spiral spring and then converted into a viscosimetric unit.

\subsubsection{Qualitative and Quantitative Analysis of the Active Substances \\ 1) Destabilization and extraction}

The emulsions were destabilized as follows: the tubes containing the emulsions were placed in an oven at a temperature of $37^{\circ} \mathrm{C}$ for one hour to liquefac- 
tion and then centrifuged at $3500 \mathrm{rpm}$ for twenty minutes. The aqueous phase is extracted using a five $\mathrm{ml}$ syringe. Thereafter, a second centrifugation of the water is carried out at $3500 \mathrm{rpm}$ for one minute for purification. We used ethanol as an extraction solvent for griseofulvin. The oil or Vaseline is introduced into the separating funnel. We gradually add the ethanol to the bulb and then perform manual stirring followed by degassing for one minute. We then debouch the bulb and then let it decant. Recovering the ethanol in a beaker separates the two phases. The oil phase or Vaseline is taken up with ethanol to carry out several extractions. The ethanolic extracts are subjected to centrifugation for purification.

\section{2) Dosage}

For the assay, we used an Agilent Technologies Cary $60 \mathrm{UV}$-visible spectrophotometer.

Thus, we prepared a saturated solution of paracetamol and griseofulvin:

- $0.0926 \mathrm{~mol} / \mathrm{l}$ of paracetamol,

- $0.0566 \times 10^{-3} \mathrm{~mol} / \mathrm{l}$ of griseofulvin.

From the stock solution of known concentration, we prepared different daughter solutions of concentrations C1, C2, C3, C4, C5, C6 of final volume $10 \mathrm{ml}$. The equations of the following lines $(\mathrm{Y}=\mathrm{aX}+\mathrm{b})$ allowed us to determine the concentrations.

- For paracetamol $\mathrm{Y}=-0.00155 \mathrm{X}+8.19947 \mathrm{R}^{2}=0.99170$;

- For griseofulvin $\mathrm{Y}=-0.00243 \mathrm{X}+2.85953 \mathrm{R}^{2}=0.99629$.

\section{Results and Discussion}

The study of the physicochemical and analytical parameters of the various emulsions has been done in the absence of light at room temperature for 28 days.

\subsection{Bottle Test}

The emulsions obtained are beige to yellow, homogeneous. The emulsions are all stable, better stability was observed with the emulsions containing $6.8 \mathrm{wt} \%$ of $\mathrm{MgO}$, especially those containing only one active substance (Figure 1).

\subsection{Emulsion Direction}

The dye test carried out weekly during the 28 days of monitoring showed emulsions with aqueous droplets of heterogeneous sizes with a dispersant phase colored red by a lipophilic dye (Soudan III) (Figure 2).

The determination of the direction of the emulsions by measuring the conductivity on the following days: $\mathrm{D}_{1}, \mathrm{D}_{7}, \mathrm{D}_{14}, \mathrm{D}_{21}, \mathrm{D}_{28}$, gave zero conductivity $(0.00$ $\mathrm{mS} \cdot \mathrm{cm}^{-1}$ ) for emulsion with $4.5 \mathrm{wt} \%$ of $\mathrm{MgO}$ (Figure 1(a)) and those with 6.8 $\mathrm{wt} \%$ of $\mathrm{MgO}$ (Figure $1(\mathrm{~b})$ ). The external phase of these emulsions is therefore apolar and therefore of the W/O type. Studies have shown that a constant value of conductivity over time is a determining criterion of stability.

\subsection{Size of Droplets}

The size of the droplets varied according to the amounts of Magnesium Oxide 


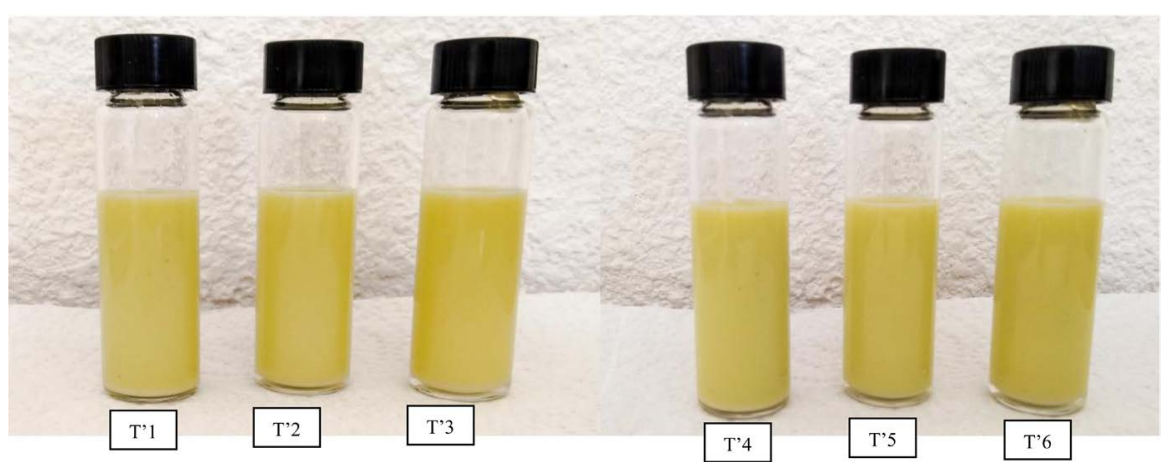

Figure 1. Aspect of tubes after 28 days of storage (emulsions with $6.8 \mathrm{wt} \% \mathrm{MgO}$ ).

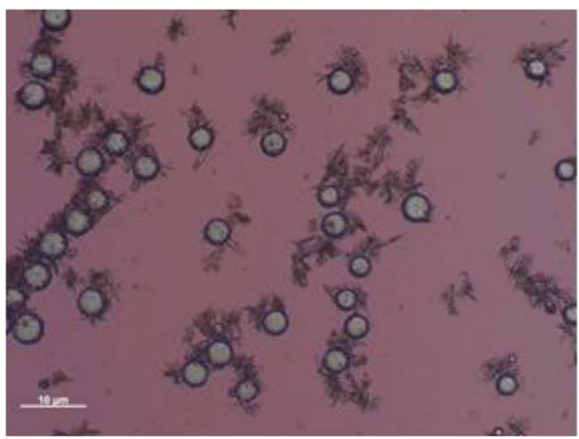

(a)

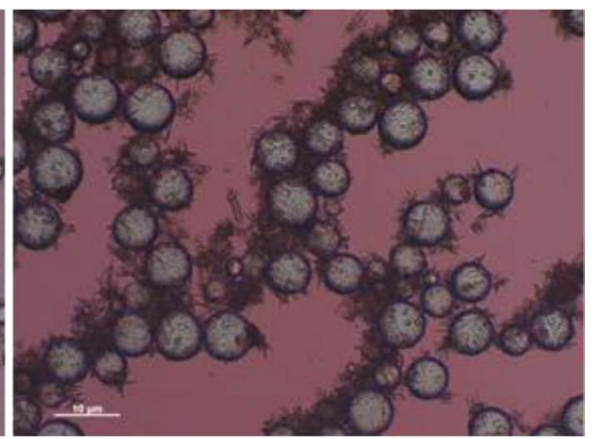

(b)

Figure 2. Pickering emulsion colored by a lipophilic dye (Soudan III). (a) 6.8 wt\% MgO, (b) $4.5 \mathrm{wt} \% \mathrm{MgO}$.

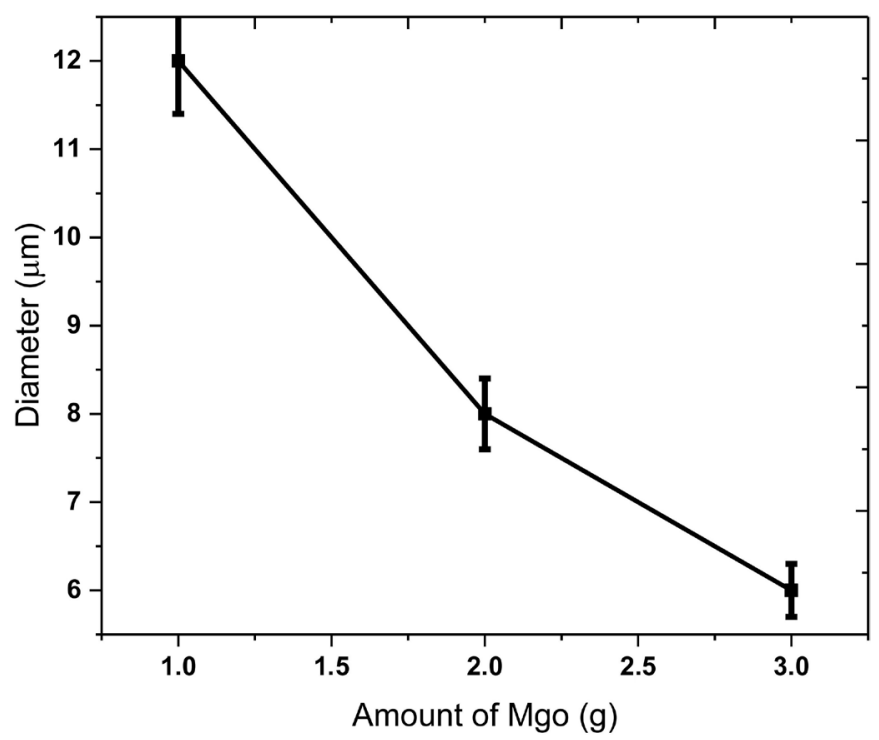

Figure 3. Evolution of the size of the droplets as a function of the amount of Magnesium Oxide.

used and the concentrations of the two active ingredients (Figure 3). We found that the size of the droplets decreased when the amount of $\mathrm{MgO}$ was increased.

The size of the droplets plays an important role in the stability of the emulsions. This is one of the variables that influence the sedimentation rate described 
by Stokes' law.

$$
v=\frac{2 r^{2} g\left(D_{1}-D_{2}\right)}{9 \mu}
$$

$V=$ sedimentation rate, $r=$ droplet radius, $g=$ acceleration due to terrestrial gravity, $D_{1} ; D_{2}=$ the respective densities of the dispersed phase and the continuous phase, $\mu=$ the viscosity of the continuous phase.

Samples containing more particles have a smaller average diameter than samples containing a smaller amount of particles. Indeed, the most probable hypothesis would be the reduction in the diameters of the drops, which is a function of the $\mathrm{MgO}$ content leading to an increase in the interfacial area. Similar results were obtained with hydrophobic silica [12]. However, the high particle concentration does not mean a dense overlap of the interface. Some authors have observed that particles are in the outer phase of the emulsion, even when the surface of the droplets is not completely covered [13] [14].

The relation between the diameter of the droplets and the interfacial area per unit volume is illustrated by the following equation [4]:

$$
D=\frac{6 \phi_{v} V}{A}
$$

$D$ is the diameter of the droplets, $A / V$ is the interfacial area per unit volume and $\phi_{v}$ is the fraction of the dispersed phase.

It should also be noted that paracetamol and griseofulvin produced an increase in the size of the droplets (Figure 4(a) and Figure 4(b)). This increase is greater with emulsions containing only paracetamol (Figure 4(a)).

Thus, the greater the quantity of active substances, the greater the size of the droplets, which leads to instability of the emulsions. Indeed, the hydrophilic properties of paracetamol ensure that it remains in the aqueous phase of the emulsion that is to say inside the droplets. This results in an increase in volume of the aqueous phase resulting in an increase in the volume per unit area. Frelichowska showed that hydrophilic caffeine destabilized Pickering type W/O emulsions by increasing the interfacial area [4].

\section{4. $\mathrm{pH}$ of the Emulsions}

In Figure 5, we show the effect of the variation of the Magnesium Oxide quantity and the concentrations of both active substances on the $\mathrm{pH}$ evolution of the emulsions. We found that the higher the amount of $\mathrm{MgO}$, the higher the $\mathrm{pH}$ of the emulsions.

Indeed, the $\mathrm{MgO}$ used is a powder of strongly basic character resulting in the basicity of the emulsions giving them a better stability. Studies have shown that a basic $\mathrm{pH}$ improves the stability of W/O emulsions [13] [15] [16]. The two active substances incorporated also played an important role on the basicity of the emulsions.

A $\mathrm{pH}$ jump was also observed on the fourteenth day of storage with $\mathrm{pH}$ values 
sometimes reaching 10 (Figure 5(b)). The two active ingredients have also played a decisive role in the basicity of the emulsions. The more paracetamol and griseofulvin was increased, the more emulsions became basic (T4, T5, T6, T'4, T'5 and T'6).
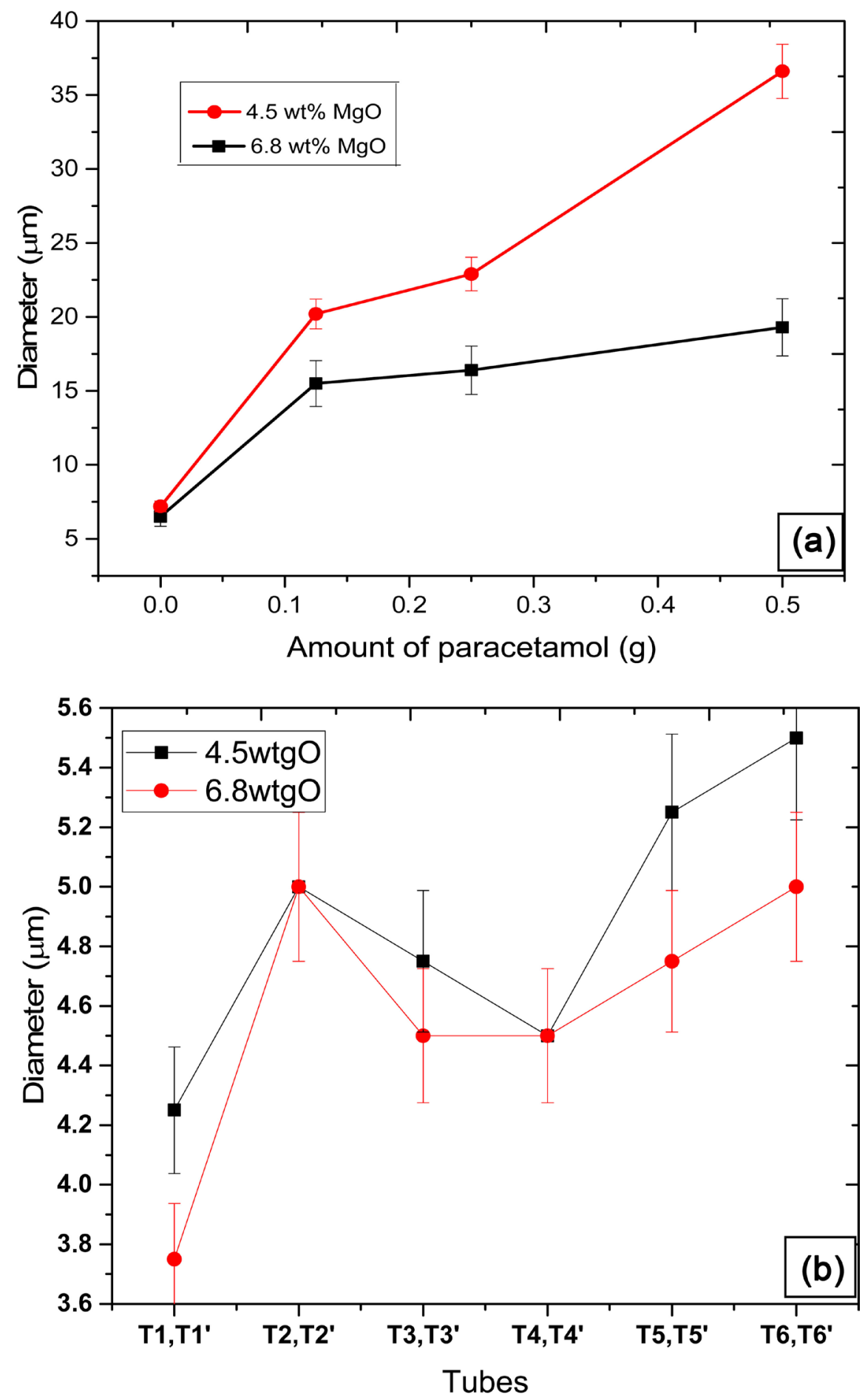

Figure 4. Evolution of the size of the droplets as a function of: (a) The amount of paracetamol incorporated, (b) The amount of paracetamol in the internal phase and griseofulvin in phase external. 

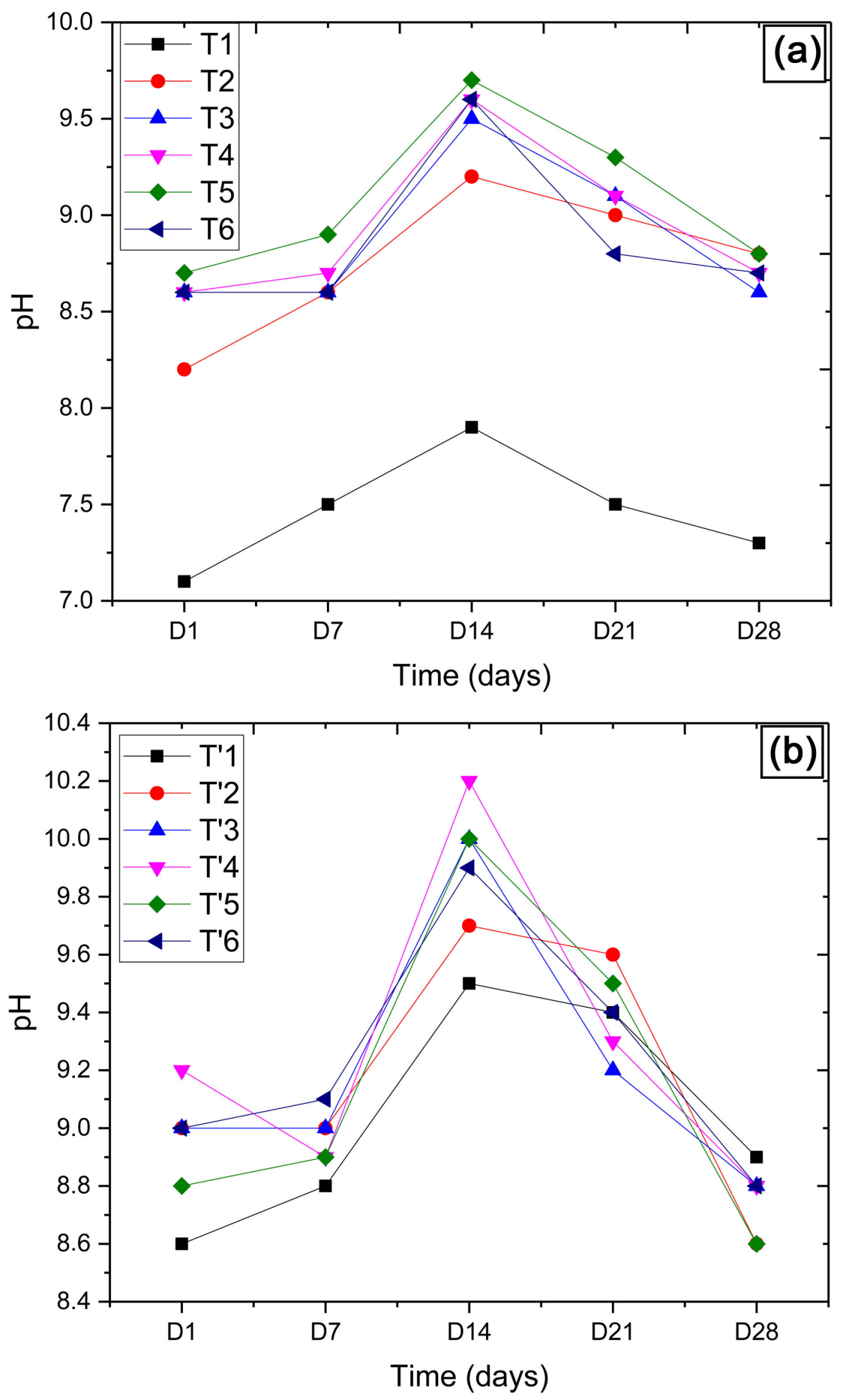

Figure 5. Evolution of the $\mathrm{pH}$ of the emulsions containing paracetamol in the internal aqueous phase and griseofulvin in the external oil phase (a) Emulsion with $4.5 \mathrm{wt} \%$ of $\mathrm{MgO}$, (b) Emulsion with $6.8 \mathrm{wt} \%$ of $\mathrm{MgO}$.

\subsection{Viscosity of Emulsions}

The viscosity of the emulsions was strongly influenced by the amount of magnesium oxide particles, paracetamol concentrations in the internal phase and griseofulvin in the external phase (Figure 6(a) and Figure 6(b)). We have found 
that a high concentration of Magnesium Oxide has led to an increase in the viscosity of the external phase of the emulsions. The tubes with $6.8 \mathrm{wt} \%$ of $\mathrm{MgO}$ have a much higher viscosity and are more stable.
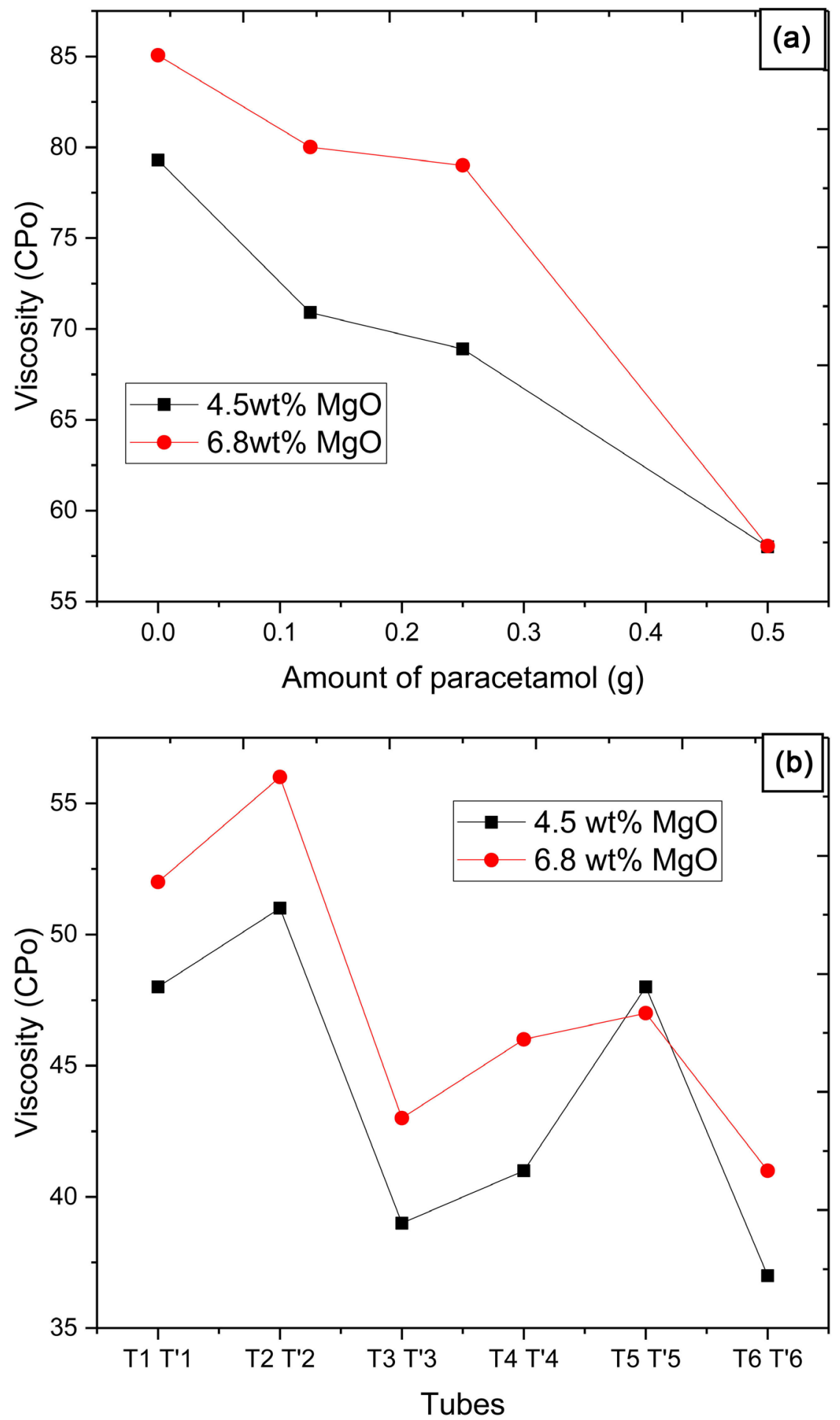

Figure 6. Evolution of the viscosity of the emulsions as a function of (a) The incorporated paracetamol, (b) The paracetamol in the internal phase and griseofulvin in the external phase. 
Studies have shown that the excess of non-adsorbed particles contributes to the stabilization of the emulsions by the formation of a three-dimensional network of flocculated particles. This improves the stability by interfering with the mutual contact of the droplets [12] [17] [18]. A similar conclusion was found by Luis Torres and al. with clay particles [19]. Thus, the increase in viscosity contributes to a better stability of the emulsions. However, it should be noted that paracetamol and griseofulvin usually reduced the viscosity of the emulsions.

\subsection{Qualitative and Quantitative Analysis of the Incorporated Active Ingredients}

\subsubsection{Destabilization and Extraction of Active Substance}

Figure 7 shows the appearance of the tubes after destabilization at the centrifuge with a clear separation of the phases.

\subsubsection{Dosage}

The use of UV-visible spectrophotometry can provide quantitative information on the concentration of a substance in a Pickering emulsion after destabilization. Indeed, this technique finds applications in the pharmaceutical field in the qualitative and quantitative analysis of pure products or mixtures such as emulsions. The encapsulated active principle can be dispersed, dissolved or adsorbed on the surface of the particles [20].

The incorporated griseofulvin was found in all extraction liquids obtained from the external oily phase. Similarly, the incorporated paracetamol was found in the aqueous phase on all the emulsions containing it initially. The concentration of griseofulvin found whatever the amount incorporated is less than $0.2 \mathrm{~g} / \mathrm{l}$, both in petroleum jelly and in oil (Figure 8 and Figure 9).

In the dispersed aqueous phase there is a large amount of paracetamol. This suggests a very good rate of encapsulation of the active principle in the dispersed phase (Figure 10). This is confirmed by the correlation between theoretical and actual concentrations of incorporated paracetamol (linear) (Figure 11).

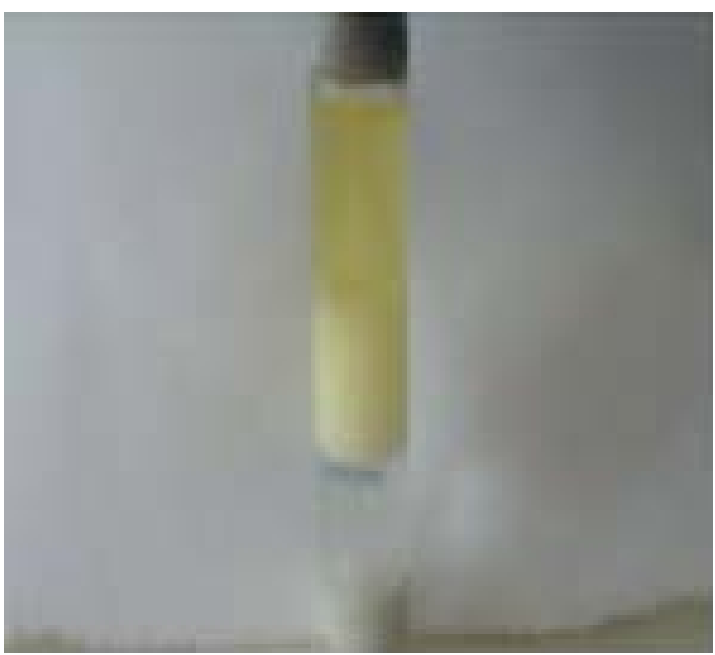

Figure 7. Aspect of tubes after destabilization. 

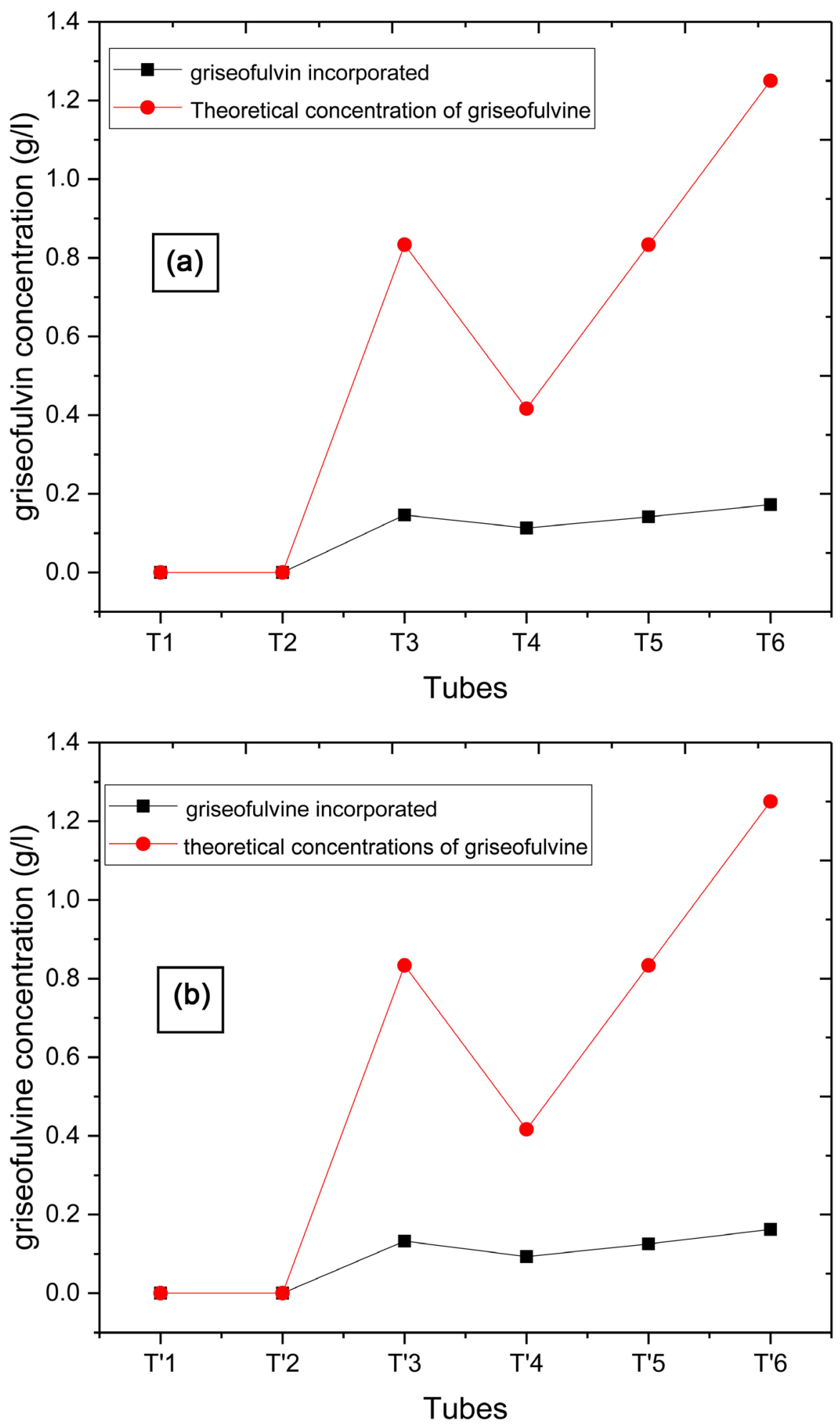

Figure 8. Evolution of the incorporated griseofulvin concentrations and those found in the external oily phase (olive oil): (a) Emulsion with $4.5 \mathrm{wt} \%$ of $\mathrm{MgO}$, (b) Emulsion with $6.8 \mathrm{wt} \%$ of $\mathrm{MgO}$. 

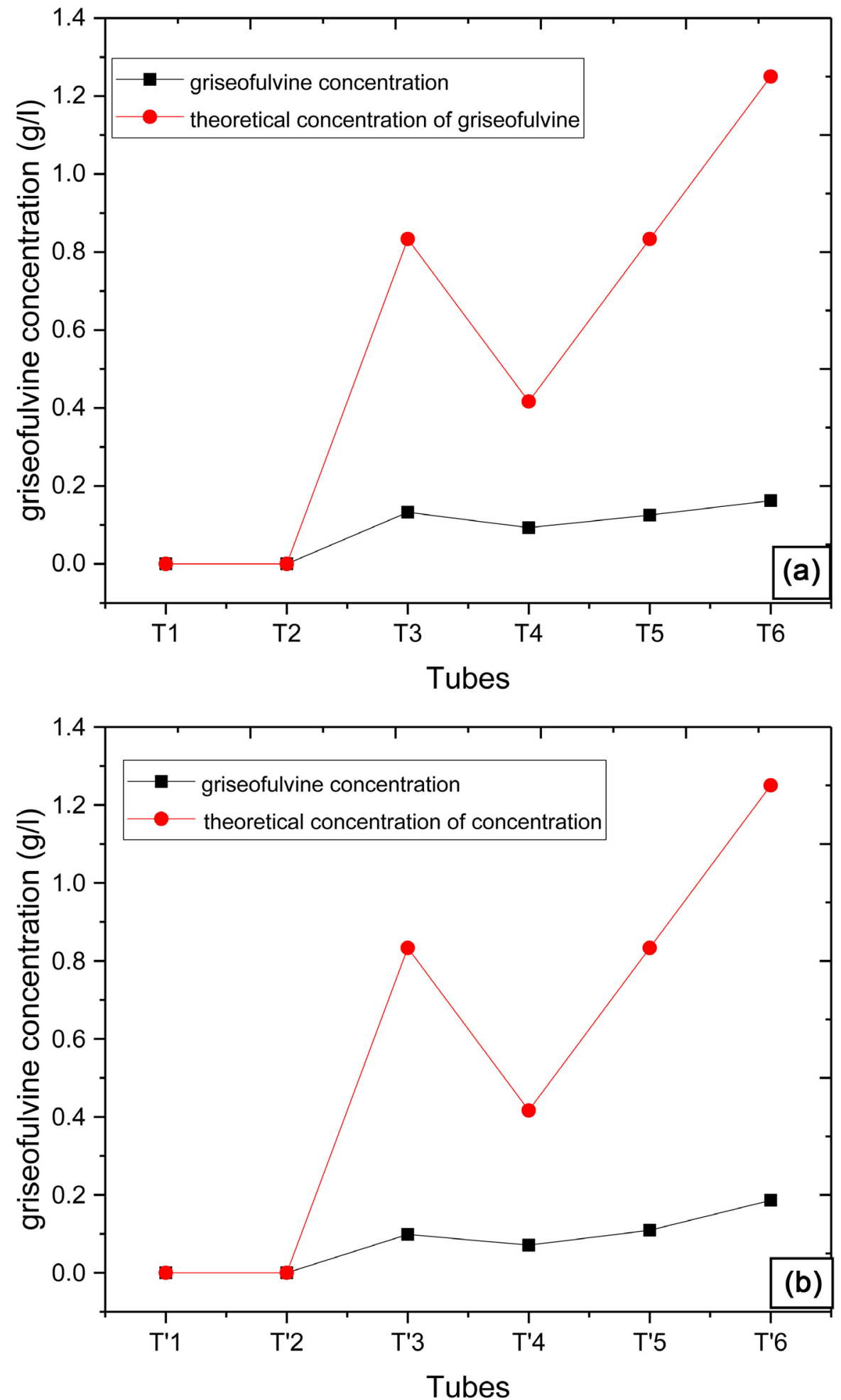

Figure 9. Evolution of the incorporated griseofulvin concentrations and those found in the external oil phase (petroleum jelly): (a) Emulsion with $4.5 \mathrm{wt} \%$ of $\mathrm{MgO}$, (b) Emulsion with $6.8 \mathrm{wt} \%$ of $\mathrm{MgO}$. 

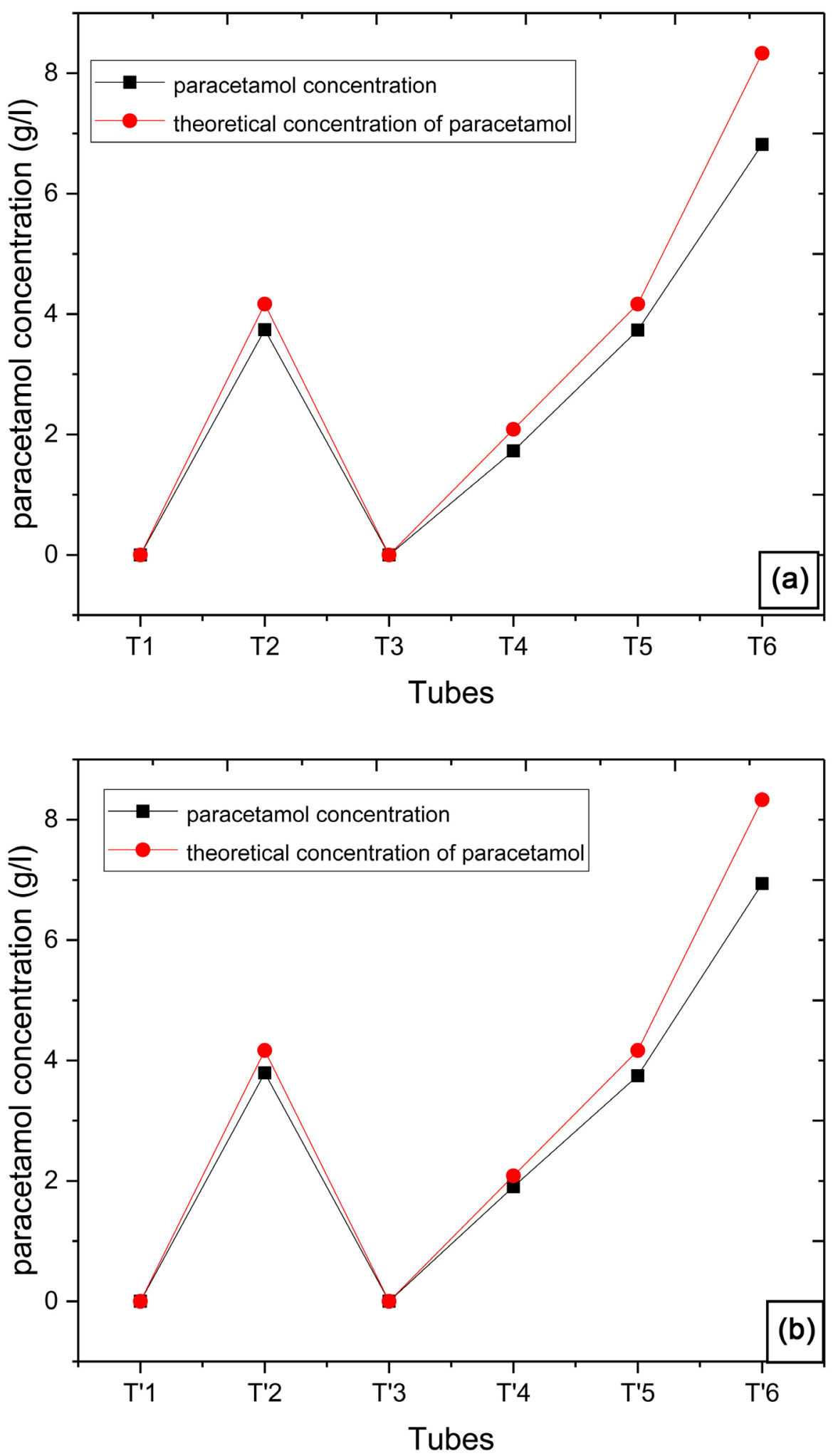

Figure 10. Evolution of the incorporated paracetamol concentrations and those found in the internal aqueous phase: (a) Emulsion with $4.5 \mathrm{wt} \%$ of $\mathrm{MgO}$, (b) Emulsion with 6.8 wt $\% \mathrm{MgO}$. 

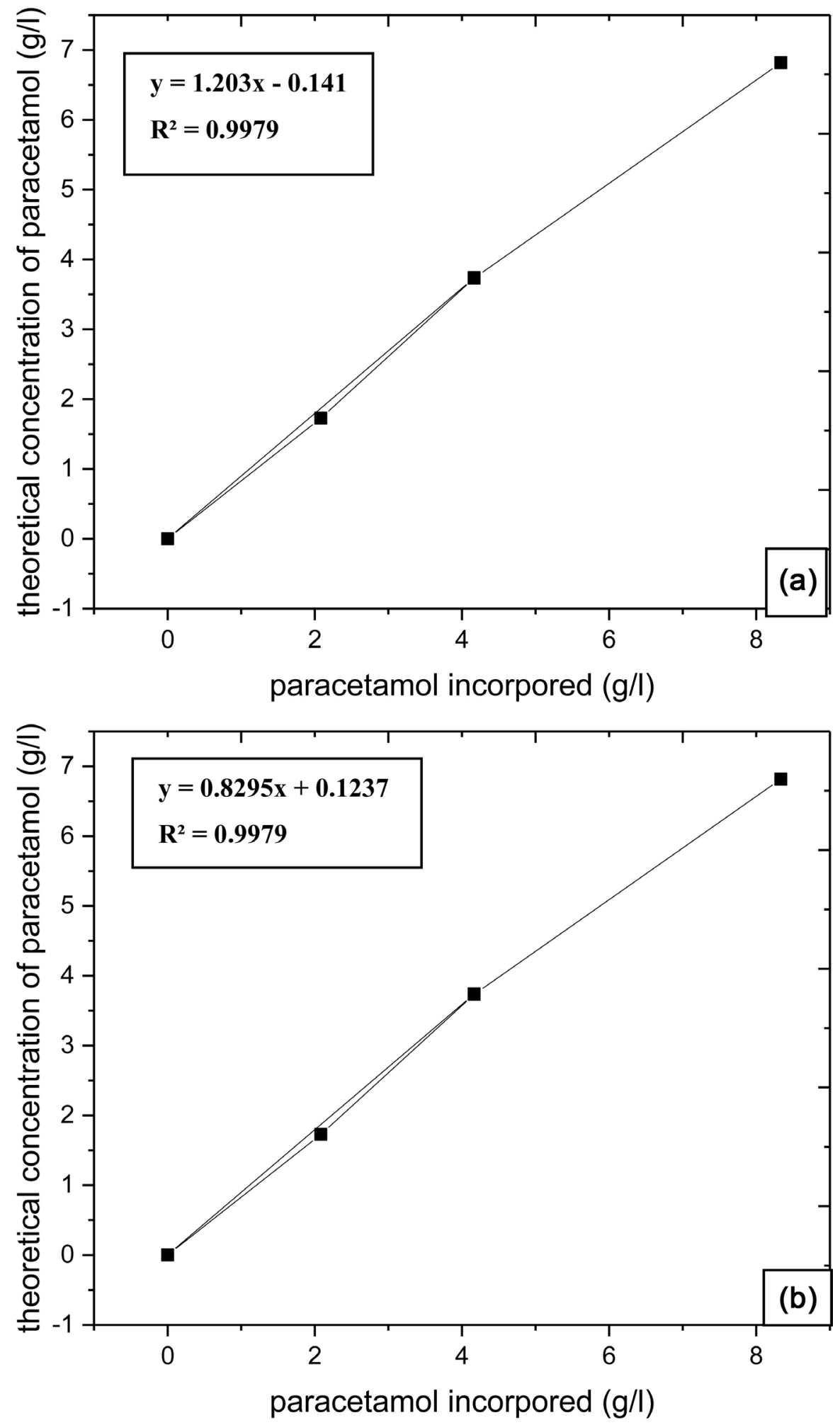

Figure 11. Correlation between the theoretical concentrations of paracetamol and those found in the internal aqueous phase: (a) Emulsion with $4.5 \mathrm{wt} \%$ of $\mathrm{MgO}$, (b) Emulsion with $6.8 \mathrm{wt} \%$ of $\mathrm{MgO}$. 


\section{Conclusion}

In view of the results obtained, we succeeded in formulating a stable $\mathrm{W} / \mathrm{O}$ type Pickering emulsion containing both griseofulvin in its external phase and paracetamol in its internal phase. Thus, this system can find a practical application in a dual therapy with the use of a single formulation. This system can also be used in therapy for the protection and encapsulation of active principles, as a reservoir system and/or as a sustained, controlled or delayed release system for active substances. This study will be supplemented by in vitro studies, and by release studies to obtain release profiles.

\section{References}

[1] Ramsden, W. (1903) The Separation of Solid Materials on the Surface of Solutions and Suspensions. Observation Concerning Surface Diagrams, Foam Blisters, Emulsions and Mechanical Coagulation. Proceedings of the Royal Society, 72, 156-164. https://doi.org/10.1098/rspl.1903.0034

[2] Pickering, S. (1907) Emulsions. Journal of Chemical Society, 91, 2001-2021. https://doi.org/10.1039/CT9079102001

Frelichowska, J. (2009) Emulsions stabilisées par des particules solides: Etudes physico-chimiques et évaluation pour l'application cutanée. Lyon University, Lyon.

[3] Chevalier Y.B.M. (2013) Emulsions Stabilized with Solid Nanoparticles: Pickering Emulsions. Colloids and Surface A: Physicochemical and Engineering Aspects, 439, 23-34. https://doi.org/10.1016/j.colsurfa.2013.02.054

[4] Frélichowska, J. (2009) Émulsions stabilisées par des particules solides: Etudes physico-chimiques et évaluation pour l'application cutanée. Thèse de doctorat Université Claude Bernard Lyon 1, n009, 211 p.

[5] Arditty, S. (2004) Materials Based on Solid-Stabilized Emulsion. Journal of Colloid Interface Science, 275, 659-664. https://doi.org/10.1016/j.jcis.2004.03.001

[6] Fouilloux, S. (2011) Nanoparticules et microfluides pour un système modèle d'émulsions de Pickering. Etude des mécanismes de stabilisation et destabilisation. Pierre et Marie Curie University, Paris.

[7] Aveyard, R.B.B. (2003) Emulsions Stabilized Solely by Colloidal Particles. Advances in Colloid and Interface Science, 100, 503-546. https://doi.org/10.1016/S0001-8686(02)00069-6

[8] Levine, S.S.E. (1985) Stabilisation of Emulsion Droplets by Fine Powders. Canadian Journal of Chemical Engineering, 62, 258-268. https://doi.org/10.1002/cjce.5450630211

[9] Abend, S.L.G. (2001) Bentonites and Double Hydroxides as Emulsifying Agents. Clay Minerals, 36, 557-570. https://doi.org/10.1180/0009855013640009

[10] Ashby, N.P.B.B. (2000) Pickering Emulsions Stabilised by Laponite Clay Particles. Physical Chemistry, 2, 5640-5646. https://doi.org/10.1039/b007098j

[11] Sharma, G.R.S. (2017) Phytoassisted Synthesis of Magnesium Oxide Nanoparticles by Swerta chirayaita. Journal of Taibah University for Sciences, 11, 471-477. https://doi.org/10.1016/j.jtusci.2016.09.004

[12] Frelichowska, J.B.M. (2010) Effect of Solid Particles Content on Properties of O/W Pickering Emulsions. Journal of Colloid and Interface Science, 351, 348-356. https://doi.org/10.1016/j.jcis.2010.08.019 
[13] Yan, N.X.C.M. (2001) On Water-in-Oil Emulsions Stabilized by Solids. Colloids and Surfaces A: Physicochemical and Engineering Aspects, 193, 97-107. https://doi.org/10.1016/S0927-7757(01)00748-8

[14] Yang, F.N.Q. (2007) Effect of Dispersion pH on the Formation and Stability of Pickering Emulsions Stabilized by Layered Double Hydroxides Particles. Journal of Colloid and Interface Science, 306, 285-295. https://doi.org/10.1016/j.jcis.2006.10.062

[15] Kim, J.H., K.S. (2004) Effect of Aqueous Phase Composition on the Stability of a Silica-Stabilized Water-in-Oil Emulsion. Ph.D. Cosmetic R and D Center, LG Household and Healthcare Research Park, 343-350.

[16] Dorobantu, L.S., Y.A. (2004) Stabilization of Oil-Water Emulsions by Hydrophobic Bacteria. Applied and Environmental Microbiology, 70, 6333-6336.

https://doi.org/10.1128/AEM.70.10.6333-6336.2004

[17] Tarimala, S., D.L. (2004) Structure of Microparticles in Solid Stabilized Emulsions. Langmuir, 20, 3492-3494. https://doi.org/10.1021/la036129e

[18] Leunissen, M.E., V.B. (2007) Electrostatics at the Oil Water Interface, Stability and Order in Emulsions and Colloids. Proceedings of the National Academy of Sciences, 104, 2585-2590. https://doi.org/10.1073/pnas.0610589104

[19] Torres, L., I.R. (2008) Pickering Emulsion Formation Aid the Removal of Creosote DNAPL from Porous Media? Chemosphere, 71, 123-132. https://doi.org/10.1016/j.chemosphere.2007.09.053

[20] Schaffazick, S., G.S. (2003) Physicochemical Characterization and Stability of the Polymeric Nanoparticle Systems for Drug Administration. Quimina Nova, 26, 726-737. https://doi.org/10.1590/S0100-40422003000500017 